\title{
Research on the Development Strategy of Fresh Food E- commerce Enterprises under COVID-19-Taking Ding Dong as an Example
}

\author{
Chang Liu ${ }^{*}$ \\ ${ }^{1}$ School of Management Studies, Shanghai University of Engineering Science, Shanghai 201620, China;
}

\begin{abstract}
During the period of the COVID-19 epidemic situation, many industries and enterprises fell into crisis due to the negative impact they have suffered. However, some industries have enjoyed a wave of dividends of epidemic situation and developed during the fight against the epidemic situation. Fresh ecommerce industry is one of them. Taking Ding Dong as an example, this paper comprehensively analyzes the reasons for its success from PEST, SWOT, market behavior, organization strategy and other aspects, and gives suggestions on highlighting platform advantages, improving service quality and improving cold chain logistics system, so as to enhance the sustainable development ability of fresh food e-commerce enterprises under the epidemic situation.
\end{abstract}

\section{Introduction:}

Since the beginning of 2020, the COVID-19 epidemic has been raging around the world. The economic and social development is facing a huge impact, and the development of countless enterprises and industries is facing unprecedented challenges. However, in recent years, the emerging fresh electricity business industry is in this special period, to show its strong creativity and vitality, ushered in a new round of development opportunities. Fresh enterprises blowout emergence is behind the fierce competition, how to stand firm in this industry, has become the major fresh electricity business enterprises first need to face the problem. In this paper, Ding Dong buy vegetables for strategic analysis, to provide suggestions for the sustainable development of fresh electricity.

\section{Background:}

The advent of the Internet era promotes the continuous renewal and progress of the industry, and fresh food ecommerce is rapidly rising in the general environment of the Internet era. China is the largest producer and consumer of fresh agricultural products. The transaction volume of the fresh produce industry has been on the rise since 2011, and the growth rate has maintained a relatively stable growth rate since 2013 (see Figure 1). Fresh food ecommerce refers to the direct sale of fresh products, such as fresh fruits, vegetables, and fresh meat, through online e-commerce. 2012 is the first year of the new development of fresh food e-commerce. Since its development, the state has continued to provide policy support. In 2016, the Central Government's No.1 document proposed to

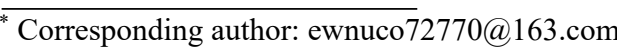

accelerate the development of rural e-commerce, form online and offline integration, and enter cities and The two-way flow pattern of consumer goods going to the countryside, and the fastest realization of innovative agricultural product circulation models through ecommerce has become the future development trend. ${ }^{[1]}$

The predecessor of Ding Dong was the Ding dong Community App, which was the first offline Ding dong in July 2014 The service station was built at the door of users, and it was the first in the world to put forward the "on demand" express service. Delivery service has also become China's earliest community front warehouse. Ding dong was officially established in In April 2017, taking community fresh food as the starting point, gathering around the life scene of three meals a day. As of October 2018, Ding Dong A total of 119 offline service stations serve most communities in Shanghai. There are nearly 700 types on its platform The products of this category involve various fruits and vegetables, meat and poultry, live fish and shrimp, daily match, etc. Adopt the "city batch Procurement + community front warehouse + 29-minute delivery" model, avoiding the "source, cold chain, cold storage" model Inherent routine to reduce supply chain costs and improve fresh food distribution efficiency and service quality.

In 2019, the annual operating income of Ding Dong is 5 billion yuan. In February 2020, when the epidemic broke out, the daily order volume of Ding Dong exceeded 600,000 , and the monthly revenue exceeded 1.2 billion yuan.

\section{PEST analysis}

PEST analysis method is from the political, economic, 
social and technical aspects of analysis. This paper refers to the policy documents, industry reports, technical indicators and other documents, collects and summarizes them, and establishes the analysis model.

\subsection{Political environment}

With the rapid development of e-commerce, the national management of e-commerce tends to be standardized and legalized. At the same time, the state is also actively formulating relevant laws and regulations to regulate and restrict e-commerce. Ding Dong as a life service ecommerce market, the formulation of national laws and regulations, can better protect the interests of Ding Dong.

In 2015, the State Council issued the "guidance on actively promoting the" Internet + "action", the central document once again focused on the Internet era, from the trend of national policies in recent years, it can be seen that China's attention to fresh electricity is also on the rise year by year. ${ }^{[2]}$

In January 27, 2016, the government issued a central document proposed to promote the domestic agricultural supply test structural reform, accelerate the transformation of agricultural development mode, improve the upstream production end at the same time, promote the development of fresh electricity business.

\subsection{Economy and Population environment}

At present, the life of most Chinese residents has reached a well-off level, and the consumption level of residents is gradually upgraded to pursue a more refined life and a higher quality of life. This increase in consumption willingness creates market opportunities and industry space for fresh electricity suppliers.

China's GDP in 2019 is expected to reach 9.9086.5 trillion yuan, an increase of 6.1 percent over the previous year, according to the Chinese Academy of Social Sciences. The per capital GDP was 70,892 yuan, an increase of $5.7 \%$ over the previous year. China has 830 million permanent urban residents, according to a report by the National Bureau of Statistics. From the above data, we can easily see that, with the improvement of people's living standard and the change of urban and rural population distribution, Ding Dong has a broad market space. $^{[3]}$

In the beginning of 2020, the sudden COVID-19 epidemic provides a once-in-a-lifetime opportunity for fresh electricity providers. Public data shows that the major fresh electricity providers achieve sales doubling. At the same time, the capital market also gives positive feedback, and the stocks of the major fresh electricity providers are all the way red.

\subsection{Social and Cultural environment}

With the development of economy and the change of times, China's consumer groups are gradually changing. At present, the post-80s and post-90s have become the main force of consumption, and their consumption habits have also changed. They are more willing to improve their consumption level, and their pursuit of quality and experience is getting higher and higher. Under the epidemic situation, many Chinese people stay at home. However, as the end of the year approaches, it is difficult for Chinese people to reduce their quality of life. The sudden inconvenience magnifies people's attention to food materials. Network to buy food, home delivery, has become the best choice.

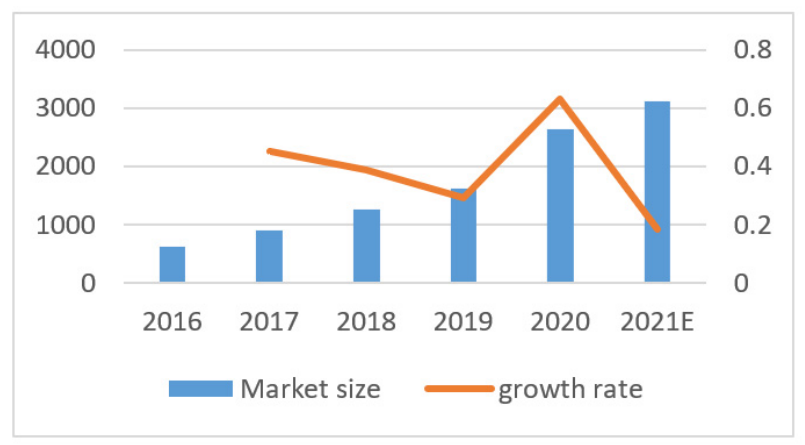

Figure 1. Market size and Forecast of E-commerce in China from 2016 to 2021

It can be seen above that the epidemic situation in 2020 has injected lots of vitality into the fresh e-commerce market. At present, the market scale of fresh e-commerce is gradually approaching a stable value.

\subsection{Technology environment}

The arrival of the information age, the increasingly developed Internet technology, the application of big data and artificial intelligence, plays a role in improving the operation and maintenance efficiency of fresh enterprises and reducing the production cost of enterprises. The technology application of big data can help fresh electricity enterprises to better manage inventory, analyze consumer preferences, and improve the efficiency of operation and maintenance. The development of the Internet of Things and cold chain logistics promotes the standardization of fresh products and reduces wastage. Technical support provide Ding Dong an excellent technical environment.

Conclusion: From the PEST model, it can be seen that Ding Dong buys with good environmental support, and fresh e-commerce is in the right time.

\section{SWOT analysis}

SWOT analysis is a scientific analysis method which combines the internal environment with the external environment from four aspects: competitive advantages, disadvantages, opportunities and threats, and formulates development plans and strategies

Through the analysis of Ding Dong's internal environment, opportunities and challenges, the SWOT matrix of Ding Dong is constructed as follows: 
Table 1. Ding Dong SWOT matrix

\begin{tabular}{|c|c|c|}
\hline & strength & weakness \\
\hline opportunity & $\begin{array}{l}\text { Local users have } \\
\text { large scale, good } \\
\text { reputation and } \\
\text { policy support }\end{array}$ & $\begin{array}{l}\text { The consumer group } \\
\text { is narrow,but in the } \\
\text { era of information } \\
\text { diversification, the } \\
\text { market potential is } \\
\text { great }\end{array}$ \\
\hline threat & $\begin{array}{l}\text { Although it has a } \\
\text { high market share } \\
\text { in Shanghai, its } \\
\text { competitors are } \\
\text { eyeing it }\end{array}$ & $\begin{array}{l}\text { The propaganda } \\
\text { channel is single and } \\
\text { there is the threat of } \\
\text { negative information }\end{array}$ \\
\hline
\end{tabular}

From the analysis of the development opportunities and advantages of Ding Dong, we can see that Ding Dong has greatly improved its online marketing effect by virtue of its strong brand strength, mode characteristics and data technology advantages. Ding Dong has a stable consumer market. In the process of developing the market, it should make use of its advantages, avoid its shortcomings, grasp the opportunities of policy, market and consumption advantages, and deal with the threat of competition, so as to obtain sustainable competitive advantages.

\section{Strategic analysis under epidemic situation}

Enterprise management strategy as the environment changes, Ding Dong, for example, compared the main offline sales of enterprises, ding-dong shopping online under the impact of the outbreak is more small, instead more led in objective environment housebound people must choose the Internet shopping such a method, for the enterprise strategic management, according to the external, and the change of market environment, In the process of promoting enterprise strategic management, it is particularly important under the influence of this epidemic.

\subsection{Take initiative to fight the epidemic}

Ding Dong took the lead in adjusting the algorithm, transforming personal distribution into block scheduling, setting up a supply guarantee team, and renting electric vehicles to improve the distribution efficiency. And on the seventh day to launch new categories like "big brands", the average price fell by $30 \%$, direct capacity increase was $30 \%$, the category of also let platform of bad review rate fell to $0.5 \%$ in the artificial prices soar up

During the epidemic period when labor prices have risen sharply, Ding Dong's measures for buying vegetables will increase net cash outflows, the overall costs and loss risk. There is great financial pressure. Although, from a financial perspective, the series of measures launched by Ding Dong in response to the epidemic will certainly have a negative impact on its financial performance, but from a long-term perspective, by attracting new users as soon as possible, consolidating its user base, and cultivating the satisfaction of existing users, Ding Dong can have a deeper foundation for its future development.
When news of the epidemic first came out, the founder and CEO of Ding Dong, organized an emergency war preparedness meeting for senior executives. "We are commodities for people's livelihood. During the epidemic, we don't look at profits or KPI!As long as the supply is guaranteed, more users can buy food." Ding Dong choose to buy vegetables at the expense of short-term interests, is for the sake of long-term development. From the market point of view, although the epidemic has caused a certain impact on Ding Dong in the short term, the fundamentals of Ding Dong are still stable. These measures will further strengthen the stickiness between Ding Dong and users, and consolidate its market competitive advantage.

In fact, during the epidemic, Ding Dong supplied 400 tons of vegetables every day in Shanghai, which won the trust of users. The strategy developed by Ding Dong during the epidemic well assumed the social responsibility of the enterprise, and meanwhile stabilized and expanded its market position in Shanghai.

\subsection{Wave north, seize the market}

After stabilizing the Shanghai market with excellent performance during the epidemic, the CEO of the company decided to go north to strive for a broader market.

It is a bold move, but one with risks and opportunities. Ding Dong's dense points lead warehouse supply mode in pro-phase requires a great deal of money, and Beijing market environment is more complex than Shanghai, combined with the daily fresh, box of competitors, such as horses and Mei Tuan in north China as supply mode of fresh old front storehouse platform, has formed a mature system in Beijing. Unfamiliar supply chains, different policy conditions and the difference in consumption habits of residents in the two places put a question mark on the success of buying food northward.

Ding Dong first carries out a one-month promotion and invests millions of yuan to attract customers. At the same time, the enterprise will adjust the supply chain in Beijing region according to the special needs of the Beijing market to maintain its relative independence.

On June 11, Ding Dong, a fresh e-commerce company that has been in Beijing for several months, released new data. It says it has more than 40 stores under construction in Beijing and plans to open more than 200 this year. Ding Dong said the monthly order volume on the platform had increased 200 per cent over a two-month period. After a firm foothold in Beijing, Ding Dong will vigorously expand the national market, step by step to the electricity supplier fresh kingdom.

\section{Suggestions:}

In order to realize the sustainable development of fresh food e-commerce enterprises, this article puts forward the following suggestions 


\subsection{Clear positioning, further develop and deepen subdivision areas}

At present, the fierce competition in the e-commerce industry is caused by the unclear positioning and serious homogenization of most e-commerce platforms, which leads to the lack of core competitiveness of the brand. The epidemic has brought huge traffic to fresh electricity suppliers. Fresh electricity suppliers can conduct in-depth research on the traffic user behavior, so as to find the more profitable market segments and carry out deep cultivation. ${ }^{[4]}$ For example, the fresh e-commerce platform can focus on the preferred procurement and sales of expensive or imported seafood and other aquatic products in the segmented field, and provide the service of direct supply of origin and exclusive supply of import. This can not only make fresh electricity business enterprises to establish a distinct brand characteristics, but also can shorten the supply chain of electricity business enterprises, improve logistics efficiency, and ensure the quality and freshness of products.

\subsection{Improve supply chain management ability and strengthen product quality management}

During the epidemic, many fresh electricity suppliers strengthened the management and control of upper supply chain, including supplier relationship management and product quality control. In the post-epidemic era, fresh electricity suppliers need to integrate the supply chain management and strengthen control. ${ }^{[5]}$ Fresh electricity suppliers can build their own agricultural production base, gather the scattered individual farmers together, and create a centralized production base. At the same time, it should also actively seek for high-quality agricultural products suppliers and strengthen the mutually beneficial cooperation with upstream suppliers to make up for the problem of insufficient capacity or insufficient capital investment of the self-established production base.

For product quality control, fresh electricity suppliers should examine the production and sales qualification of their products, check the quality of their products, carry out continuous relationship management and commodity quality assessment, increase the intensity of the punishment of unqualified products.

\subsection{Innovate and upgrade business model, transition to digital operation}

Under the impact of the new retail model of digital economy, fresh e-commerce platform should also consider timely transformation, and apply new technologies such as the Internet of Things, big data, cloud computing in their own operation and development. For example, from the perspective of customers, Daily You Xian subdivides customers and data user behaviors by using the consumption habits of APP, so that different users can be screened for product categories and targeted sales.

From the perspective of supply chain, fresh electricity suppliers can digitally store and record the circulation path of fresh products from the origin, and trace the quality of fresh products. ${ }^{[6]}$ According to different commodity characteristics and order requirements for warehousing management and distribution arrangements, through intelligent order management to track the order, guarantee the quality of goods, improve the efficiency of logistics operation.

\section{Conclusion}

The new crown epidemic has brought opportunities for fresh food e-commerce companies, but also brought many challenges. Therefore, how to seize the opportunity of the epidemic to develop rapidly is particularly important.

Faced with the fierce competition and profitability problems of fresh food e-commerce companies, fresh food e-commerce companies should take active measures to identify their own positioning and form brand characteristics. At the same time, it will make full use of new technologies to transform and upgrade its business model, build its own "moat", and strive to retain the dividends brought about by the epidemic.

\section{References:}

1. Wang Xiangyang. Look at e-commerce under the epidemic[J]. Innovation World Weekly, 2020(05): 20$21+6$.

2. Ge Jihong, Wang Wenhao, Tang Yingmei. my country's fresh food e-commerce development model and analysis of its applicable conditions[J]. Guizhou Social Sciences, 2018(01): 133-138.

3. Li Yuan, Li Jing. Fresh agricultural products $\mathrm{O} 2 \mathrm{O}$ ecommerce model and improvement strategy under the background of "Internet +"[J]. Business Economics Research, 2020(20): 96-99.

4. Zheng Hongming, Wu Xiao. Research on fresh food e-commerce business model[J]. China Management Information, 2019, 22(15): 130-132.

5. Wang Shenghua. Study on the quality and quality safety of fresh agricultural products Integration perspective [J]. Shanxi Agricultural Economics, 2020 (15): $14-15$

6. Zeng Dingqian, Tong Mingliang.Study on the ability integration and improvement of fresh food ecommerce supply chain[J]. Economic Research, 2020(18): 105-108. 